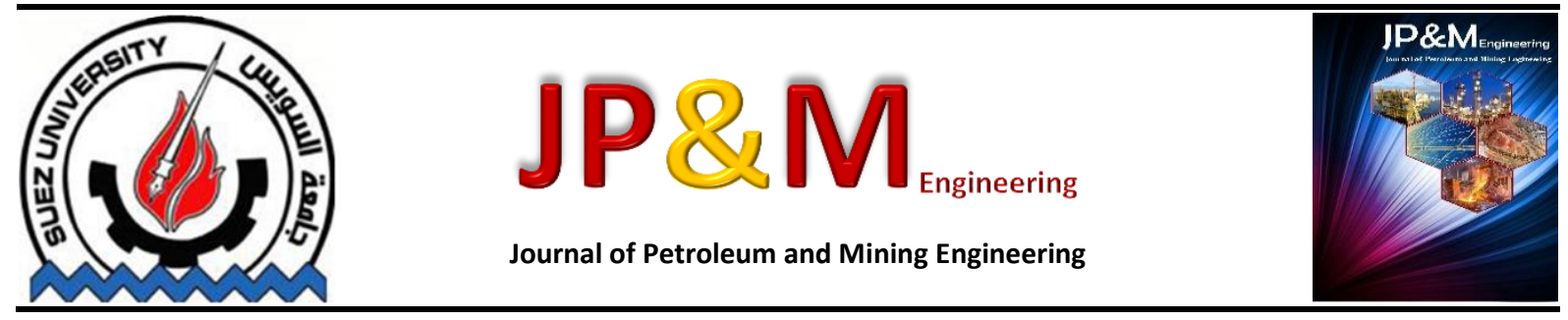

\title{
An Analytical Model of Heat Generation for Friction Stir Welding
}

\section{Using Bobbin Tool Design}

\author{
M.I.A. Habbaa, ${ }^{*}$, M. M. Z. Ahmed ${ }^{b, c}$, Mohamed M. El-Sayed Seleman ${ }^{b}$, A. EL-Nikhaily ${ }^{a}$ \\ aMechanical Department, Faculty of Industrial Education, Suez University, Egypt. \\ ${ }^{b}$ Metallurgical and Materials Engineering Department, Faculty of Petroleum and Mining Engineering, Suez University, Egypt. \\ c Mechanical Engineering Department,The British University in Egypt, El-Sherouk City, 11837 Cairo, Egypt \\ *Corresponding author e-mail: mohamed.atia@suezuniv.edu.eg
}

\section{Keywords}

Friction Stir Welding; AA1050; Bobbin tool; An analytical model; Heat generation.

\begin{abstract}
A mathematical model for heat generation for bobbin tool friction stir welding (BTFSW) is proposed. The model applies on bobbin tool with Cylindrical pin to weld AA1050 alloy. The BT-FSW joints are welded at various travel speeds $(200,400,600$, 800 , and $1000 \mathrm{~mm} / \mathrm{min}$ ) and constant rotation speed of $600 \mathrm{rpm}$. In the proposed model, only the heat generated by friction is considered. The proposed mathematical model was validated with measured results. The BT-FSW heat generation increase with increasing bobbin rotation speed, friction coefficient, shoulder radius, and pin radius. On the other hand, the heat generation decrease with increasing bobbin tool travel speed.
\end{abstract}

\section{Introduction}

Bobbin tool friction stir welding (BT-FSW) is an innovative tool design. The name "bobbin" refers to the shape of the tool that consists of two shoulders; one acting on the lower and one on the upper surface of the welded plate, connected with a pin [1], [2]. The bottom shoulder replaces the backing plate used in conventional tool friction stir welding (CT-FSW). A BTFSW leads to low distortion, due to uniform heat generation and eliminates weld roots, and root defects [1]. The heat generated during FS process has a strong effect on the weld quality. The FSW heat generates from friction (sliding condition) and plastic deformation (sticking condition) at the interface surfaces between the FSW tool and workpiece [2]. Bastier et al [3]. reported the frictional heat is $95.6 \%$. Therefore, several studies assume that, FSW heat is generated by frictional heat only. Since the development of the FS process, many articles have been published on CT-FSW thermal model [4]-[10]. and have focused on the relationship between the weld temperature and CT-FSW with different pin geometries. However, a little has been published on mathematical modelling of heat generated by BT-FSW [11].

The aim of present study is to develop a mathematical model to predict the heat generated in BT-FSW with cylindrical pin using different process parameters.

\section{General equations of heat generation in BT-FSW}

The BT-FSW process is shown schematically in Figure 1. In general, during BT-FSW, a rotating tool with two shoulders moves along the workpiece interface. As the bobbin tool (BT) moves along the workpiece, heat is generated at the interface. During BT-FSW the total heat generated at the different portions Qt is the summation of heat generated (Eq. 1 ) at the upper $Q_{u s}$ and lower $Q_{l s}$ shoulder surfaces and pin surface $Q_{p s}$.

$Q_{t}=Q_{u s}+Q_{l s}+Q_{p s}$

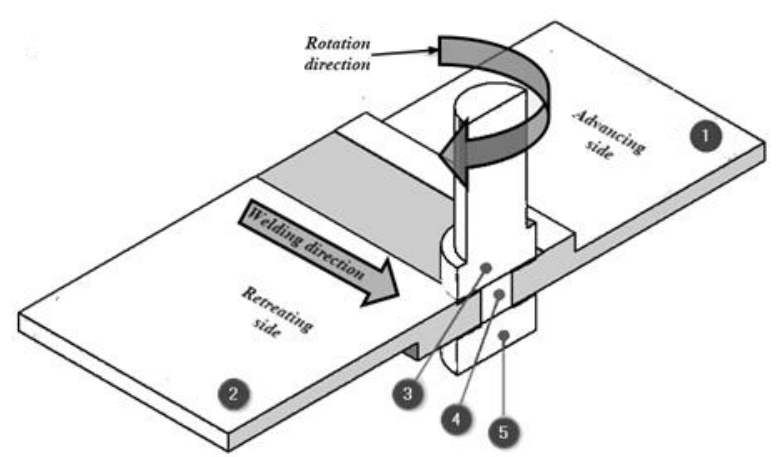

Figure 1 schematics of BT-FSW process. 1)lower plat, 2) upper plat, 3) upper shoulder, 4) pin, and 5) lower shoulder 
In general, the FSW heat is generated through plastic deformation (Sticking) and friction (sliding) between FSW tool and workpiece[10], [12], [13]. The following Expression 2, 3 and 4 consider both sources of heat generation and their effect on each other.

$Q_{u s}=\left(1-\varphi_{u s}\right) Q_{u s . f r}+\varphi_{u s} Q_{u s . d}$

$Q_{l s}=\left(1-\varphi_{l s}\right) Q_{l s . f r}+\varphi_{l s} Q_{l s . d}$

$Q_{p s}=\left(1-\varphi_{p s}\right) Q_{p s . f r}+\varphi_{p s} Q_{p s . d}$

Previous studies [14], [15] showed, $\varphi=0$, full sliding condition is applied, and heat is generated by friction only, but if $\varphi=1$ heat is generated by plastic deformation only with full sticking condition, according to, $\varphi u s=\varphi l s=0.2$ and $\varphi_{p s}=0.1$.

The value of $\phi$ is typically very small. For example, $P$ Heurtier, et al [5] estimated the value to be 0.1 and Schmidt [16] and C Hamilton [17] reported that, if a little of sticking condition occurs, the frictional shear stress must be equal to the yield shear stress of the material, so that, Eqs. 2, 3, and 4 can be rewritten as:

$Q_{u s}=Q_{u s f r}$

$Q_{l s}=Q_{l s f r}$

$Q_{p s}=Q_{p s f r}$

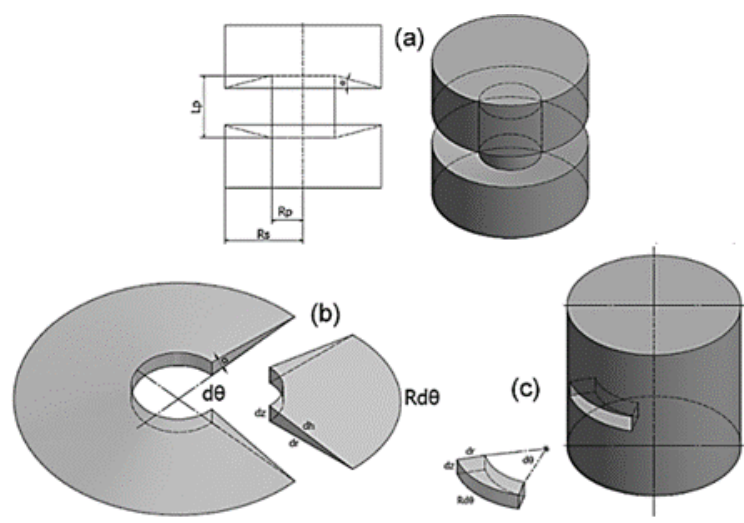

Figure 2 a) Schematic drawing of BT-FSW with cylindrical pin, b) upper or lower shoulder contact surface and c) cylindrical Pin contact surface.

The general equations of friction and deformation heat generation at different portions of BT shown in Figure 3 depend on the angular velocity $(\omega)$ and the applied total torque $(M)$, and are given by [10], [13], [14]:

$d Q_{f}=\omega d M=\omega R d F=\omega R \tau_{s} d A$

The heat generated by sliding is related to the contact shear stress [13], [18] and is given by Eq. 9: $\tau_{s}=\mu p$ for sliding conditon

From previous works [10], [14], [15], [17], [19], the coefficient of friction $(\mu)$ decreases with increasing temperature at the contact between the tool and workpiece interfaces and $\mu$ varies between 0.4 and 0.5 depending on the FS parameters. However, if heat generation exceeds $2000 \mathrm{~J} / \mathrm{mm}, \mu$ is reduced to 0.45 , and if it exceeds $3000 \mathrm{~J} / \mathrm{mm}, \mu$ is reduced to 0.4 . The coefficient of friction $(\mu)$ can be calculated as:

$$
\mu=\mu_{o}\left[1-e^{-\delta \frac{\omega R_{m}}{\omega_{o} R_{s}}}\right]
$$

For present work static friction coefficient $\mu_{o}$ is taken as 0.45 , and the rotating speed $\omega$ as well as the rotation speed reference $\omega_{o}$ is taken as $400 \mathrm{rpm}$ and
$R_{m}, R_{s}$ are the pin and shoulder radii. and it is taken as 0.4 .

For BT-FSW, the gap between the two shoulders is equivalent to the thickness of workpiece, and the pressure $(p)$ acting on the BT shoulders results from the thermal expansion of the workpiece. When the BT-FSW begins the welding temperature increases and the thickness of workpiece increases and exerts a pressure in $\mathrm{Z}$ direction on the BT shoulders. The value of $p$ increases with increasing Rs/Ts ratio until $p$ reaches the temperature dependent yield stress $\sigma y . t$ of materials. Beyond this point, the value of $p$ becomes equivalent to $\sigma y$. The temperature dependence of the oy.t is presented by [20]:

$\sigma_{y \cdot T}=\sigma_{y}\left[1-\left(\frac{T_{1}-T_{R}}{T_{m}-T_{R}}\right)\right]$

\section{Heat generation for BT-FSW with cylindrical pin}

\section{Heat generation by BT-FSW at shoulders}

The frictional heat generation $d Q_{\text {us.f }}$ at upper concave and lower concave shoulder is given by: $d Q_{u s}=\omega R \tau_{s} d \theta d r$

$d Q_{u s}=\frac{\omega R^{2} \tau_{s}}{\cos \alpha} d \theta d r$

Integration of Eq.14 gives the heat generation at upper shoulder surface

$Q_{u s}=\int_{0}^{2 \pi} \int_{R_{p}}^{R_{s}} \frac{\omega R^{2} \tau_{s}}{\cos \alpha} d \theta d r=2 \pi \omega \tau_{s}\left(R_{s}^{3}-R_{p}^{3}\right) / 3 \cos \alpha$

For BT-FSW, the heat generated at the lower shoulder is the same as heat generated at the upper shoulder, and is given by:

$Q_{l s}=2 \pi \omega \tau_{s}\left(R_{l s}^{3}-R_{p}^{3}\right) / 3 \cos \alpha$

The sum of heat generated at both shoulders will be let used $Q_{2 s}$ and given by:

$Q_{2 s}=\left[\frac{2 \pi \omega \tau_{s}\left(R_{u s}^{3}-R_{p}^{3}\right)}{3 \cos \alpha}\right]+\left[\frac{2 \pi \omega \tau_{s}\left(R_{l s}^{3}-R_{p}^{3}\right)}{3 \cos \alpha}\right]$

\section{Heat generation by BT-FSW at cylindrical pin surface}

The dimensions of bobbin tool and infinitesimal element for cylindrical pin surface are presented in Fig $2 \mathrm{~b}$ and Figure 3. The frictional heat generation $Q_{p s}$ at infinitesimal element for pin surface is given by Eq. 17.

The integration of Eq.18 determines the heat generation of the pin surface.

using Eqs. 16, and 18 the total heat generation for BT-FSW with concave shoulders and cylindrical pin is given as Eq. 19.

Using Eq.16 and Eq.19 the heat generation for concave shoulders is given by Eq. 20.

For pin, the portion of heat generation given by Eq. 21. For BT-FSW with concave shoulder, the energy per unite length is given by Eq.22, and the energy per unite length for BT-FSW with flat shoulders is given by Eq. 23.

$d Q_{p s}=\omega R_{p}^{2} \tau_{s} d \theta d z$ 


$$
\begin{aligned}
& Q_{p s}=\int_{0}^{2 \pi} \int_{0}^{l_{p}} \omega R_{p}^{2} \tau_{s} d \theta d z=2 \pi \omega l_{p} R_{p}^{2} \tau_{s} \\
& Q_{t . c}=\left[\frac{2 \pi \omega \tau_{s}\left(R_{u s}^{3}-R_{p}^{3}\right)}{3 \cos \alpha}\right] \\
& +\left[\frac{2 \pi \omega \tau_{s}\left(R_{l s}^{3}-R_{p}^{3}\right)}{3 \cos \alpha}\right]+\left[2 \pi \omega l_{p} R_{p}^{2} \tau_{s}\right] \\
& p_{2 s c}=\frac{Q_{2 . s}}{Q_{t . c}} \\
& =\frac{\left[\left(R_{u s}^{3}-R_{p}^{3}\right) / 3 \cos \alpha\right]+\left[\left(R_{l s}^{3}-R_{p}^{3}\right) / 3 \cos \alpha\right]}{\left[\frac{\left(R_{u s}^{3}-R_{p}^{3}\right)}{3 \cos \alpha}\right]+\left[\frac{\left(R_{l s}^{3}-R_{p}^{3}\right)}{3 \cos \alpha}\right]+\left[\omega l_{p} R_{p}^{2}\right]} \\
& p_{p s . c}=\frac{Q_{p . s}}{Q_{t . c}} \\
& =\frac{\omega l_{p} R_{p}^{2}}{\left[\frac{\left(R_{u s}^{3}-R_{p}^{3}\right)}{3 \cos \alpha}\right]+\left[\frac{\left(R_{l s}^{3}-R_{p}^{3}\right)}{3 \cos \alpha}\right]+\left[\omega l_{p} R_{p}^{2}\right]} \\
& Q_{E l . c}=\frac{2 \pi \mu \omega p}{T_{s}}\left[\left[\frac{\left(R_{u s}^{3}-R_{p}^{3}\right)}{3 \cos \alpha}\right]+\left[\frac{\left(R_{l s}^{3}-R_{p}^{3}\right)}{3 \cos \alpha}\right]\right. \\
& \left.+\left[l_{p} R_{p}^{2}\right]\right] \\
& \begin{array}{c}
Q_{t . f}=\left[\frac{2 \pi \omega \tau_{s}\left(R_{u s}^{3}-R_{p}^{3}\right)}{3}\right]+\left[\frac{2 \pi \omega \tau_{s}\left(R_{l s}^{3}-R_{p}^{3}\right)}{3}\right] \\
+\left[2 \pi \omega l_{p} R_{p}^{2} \tau_{s}\right]
\end{array}
\end{aligned}
$$

\section{Results}

Figure 3 presents the effect of BT-FSW process parameters on heat generation at a various rotation speeds from 100 to $1000 \mathrm{rpm}$ and various travel speeds from 100 to $1000 \mathrm{~mm} / \mathrm{min}$. the heat generation is directly proportional to the rotation speed and inversely proportional to travel speed. However, if BT-FSW is applied with increasing rotation speed and decreasing travel speed, the BT-FSW heat generation is increased. This is because the increase of heat generation leads to an easier material flow and vice versa.

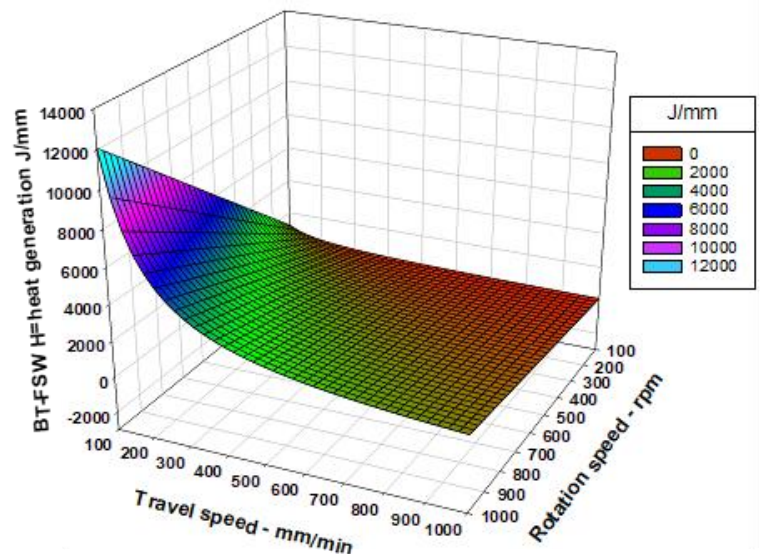

Figure 3 Effect of rotation and travel speeds on BT-FSW heat generation.

Figure 4 shows the effect of friction coefficient $(\mu)$ from zero to 0.8 on BT-FSW heat generation, at different process parameters ( $\mathrm{rpm}$ and $\mathrm{mm} / \mathrm{min}$ ), at the same rotation and travel speed, the heat generation increases linearly with friction coefficient.

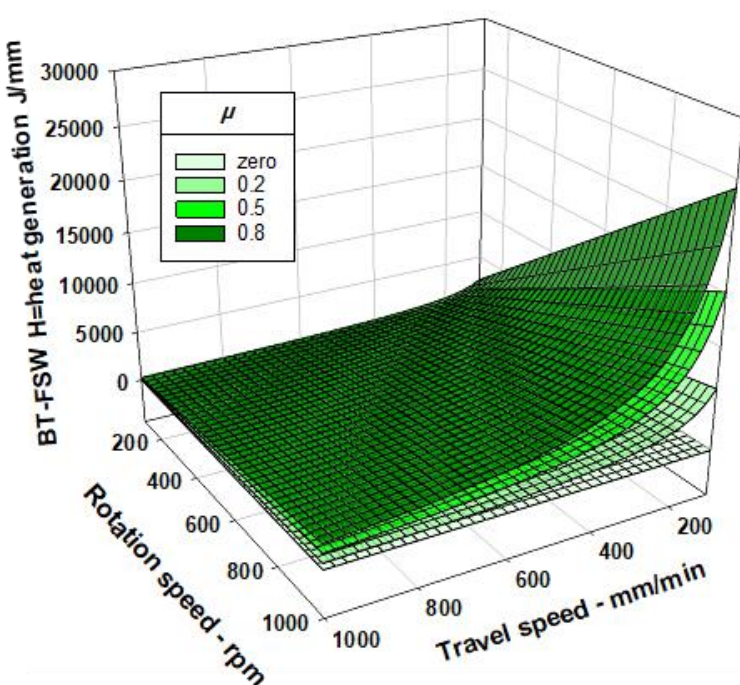

Figure 4 Effect of friction coefficient $(\mu)$ on BT-FSW heat generation.

Figure 5 and Figure 6 present the effects of shoulders and pin diameters on the BT-FSW heat generation respectively. From Figure 7 indicates that heat generation increases significantly when the shoulder radius increases from 0 (Pin only) to $20 \mathrm{~mm}$. A similar trend is found in Figure 8 when the pin radius increases the heat generation is also increased. Increasing BT-FSW pin and shoulder radius increasing heat generation due to the increases of contact surface between BT and workpiece.

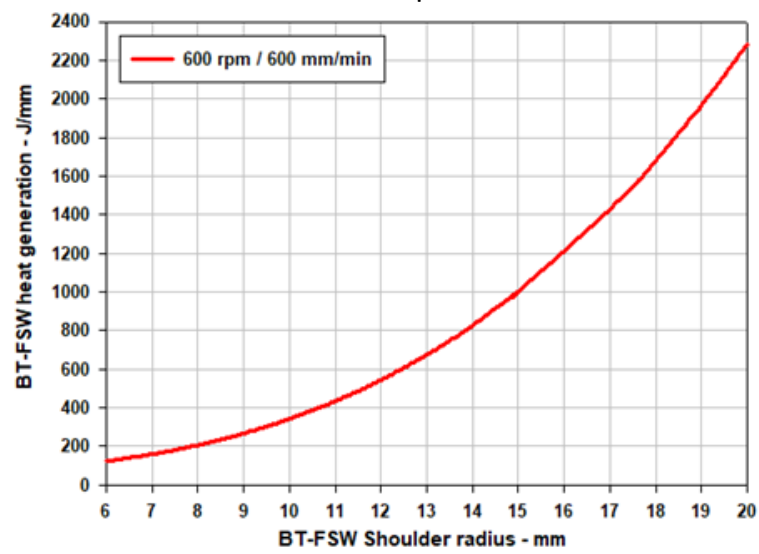

Figure 5 Effect of BT-FSW shoulder radius on BT-FSW heat generation.

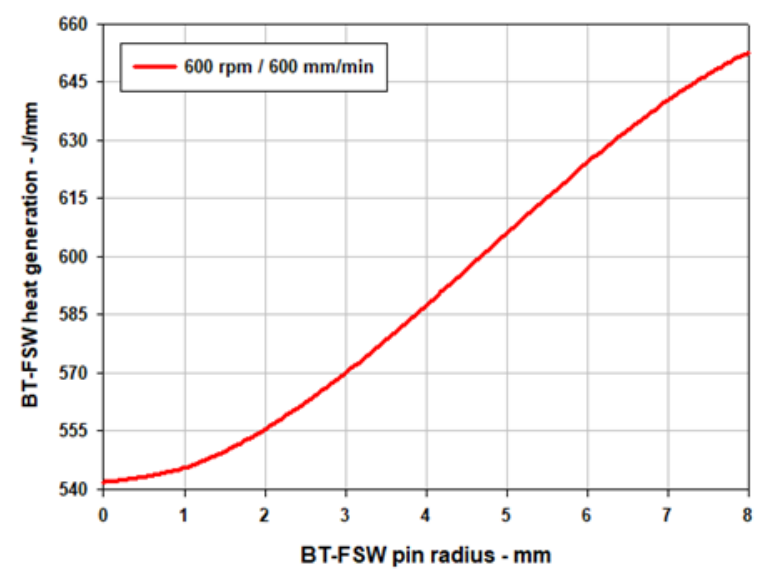

Figure 6 Effects of BT-FSW pin radius on the heat generation. 
Figure 7 shows the BT-FSW with flat shoulders and different angles of concave shoulders using different rotation speeds, the heat generation is directly proportional to the angle of concave shoulder, and is higher than with a flat shoulder, and it increases with increasing shoulder angle from 0 to 9o, due to the increase of the contact surface between shoulders and workpiece.

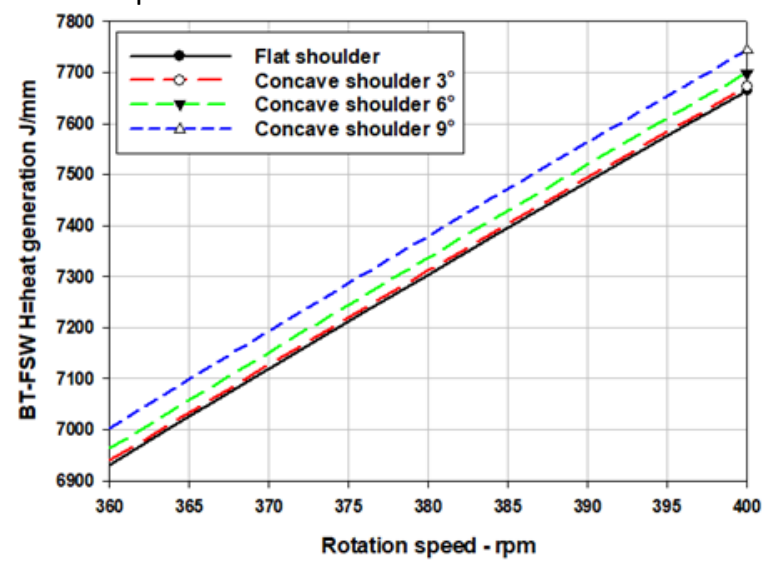

Figure 7 Effect of concave shoulder angle on the total heat generation.

\section{Model validation}

Table 1 presents the BT-FSW tool description of 10 $\mathrm{mm}$ thick AA1050 aluminum alloy. Figure 8 displays the temperature ratio Tw/Ts vs. BT-FSW heat generation per unit length with a nonlinear regression curve. The multiple correlation coefficient, $R$ is 0.99 , the coefficient of determination, $R 2$ is 0.99 , and the standard error of the estimate, $\mathrm{Sx}$, is 0.002 . The relationship between the Tw/Ts and the BT-FSW heat generation per unit length can be expressed by the following empirical Eq. 24:

$$
\begin{aligned}
\frac{T_{w}}{T_{S}}=[0.2715+(2 & \left.* 10^{-4} * Q_{E l}\right)+\left(-2.69 * 10^{-8}\right. \\
& \left.\left.* Q_{E l}{ }^{2}\right)\right]
\end{aligned}
$$

Table 1 BT-FSW tool specifications and process parameters.

\begin{tabular}{|c|c|}
\hline \multicolumn{2}{|c|}{ BT-FSW tool description } \\
\hline $\begin{array}{c}\text { Upper and } \\
\text { Lower } \\
\text { shoulder }\end{array}$ & $\mathrm{D}=25 \mathrm{~mm}$ \\
\hline $\begin{array}{c}\text { Shoulder } \\
\text { surface }\end{array}$ & $\begin{array}{c}\text { Concave }(\approx 60) \text { and } \\
\text { cavities }\end{array}$ \\
\hline $\begin{array}{c}\text { Pin } \\
\text { Dimensions }\end{array}$ & Cylindrical $-10 \mathrm{~mm}$ Dia \\
\hline $\begin{array}{c}\text { Pin profile } \\
\text { “PP” }\end{array}$ & Smooth \\
\hline Shoulder Gap & $9.5 \mathrm{~mm}$ \\
\hline
\end{tabular}

Table 2 shows the BT-FSW parameters, calculated heat generation per unit length for all BT portions, and calculated peak temperatures (Tw) compared with the measured temperatures during BT-FSW of AA1050 studied in this work. Figure 9 show the effect of BT travel speed at constant rotation speed on the heat generation using $\mathrm{Cy}$ pin. the model results have the same trend as the measured values.

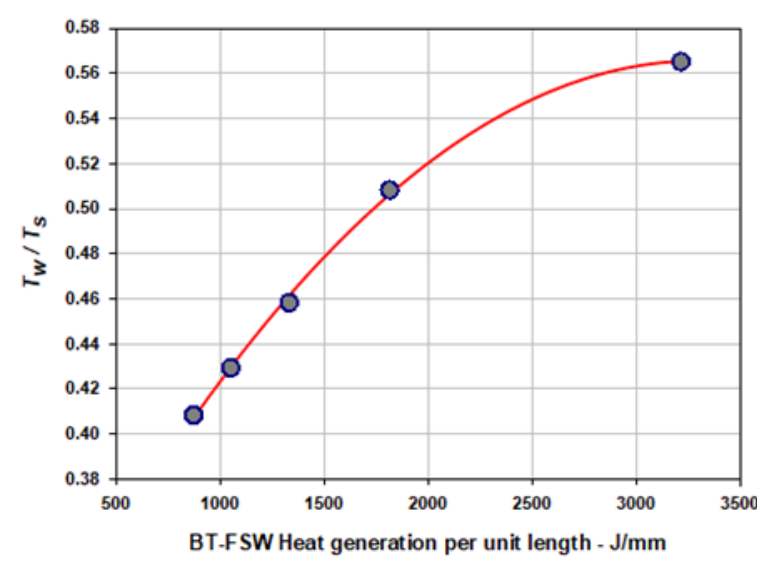

Figure 8 Temperature ratio vs. BT-FSW heat generation per unit length.

Table 2 Measured and calculated values of BT-FSW

\begin{tabular}{|c|c|c|c|c|c|}
\hline & 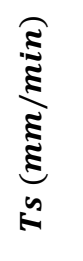 & 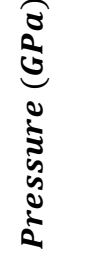 & 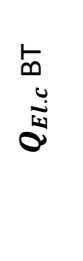 & $\vdash \frac{\bar{q}}{\bar{\delta}}$ & 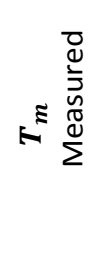 \\
\hline \multirow{5}{*}{ 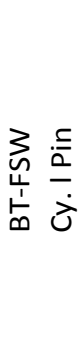 } & 200 & 0.0466 & 3218 & 377 & 367 \\
\hline & 400 & 0.0527 & 1817 & 333 & 330 \\
\hline & 600 & 0.0580 & 1334 & 301 & 298 \\
\hline & 800 & 0.0611 & 1054 & 279 & 279 \\
\hline & 1000 & 0.0634 & 875 & 263 & 265 \\
\hline
\end{tabular}
process.

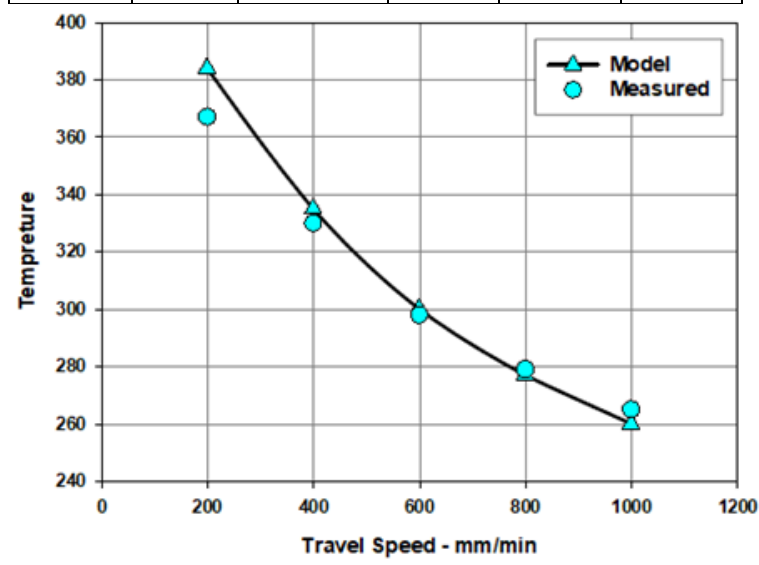

Figure 9 Temperature of BT-FSW weld zone at various travel speeds using Cy pin.

\section{Conclusion}

A mathematical model for heat generation for BTFSW with cylindrical pin was developed. Based on present results, it could be concluded that:

- The BT-FSW heat generation increases with the increase rotation speed and decreases with increasing travel speed. 
- The BT-FSW heat generation increases with increase of bobbin tool dimensions such as shoulder and pin radius.

- The friction coefficient, travel speed, rotation speed, tool dimension have strong effects on BTFSW heat generation. On the other hand, concave angle of shoulder has not effects on heat generation.

- The model results are in good agreement with the measured values of welding temperature for bobbin tool with cylindrical pin.

\section{Nomenclature}

$\mathrm{Q}_{\mathrm{t}} \quad$ total heat generation (W)

$Q_{\text {us }} \quad$ heat generated by upper shoulder, W

$Q_{l s} \quad$ heat generated by lower shoulder, W

$Q_{p} \quad$ heat generated by pin, W

fr friction

d deformation

$\phi \quad$ the extent of slip between the tool and the workpiece

$\tau_{s} \quad$ frictional shear stress, $\mathrm{mm}^{2}$

$d A$ area of the infinitesimal element, $\mathrm{mm}^{2}$

$\mathrm{p}$ pressure, GPa

u friction coefficient

$\sigma_{y} \quad$ yield stress, $\mathrm{MPa}$

$\mathrm{T}_{\mathrm{m}} \quad$ solidification temperature. $\mathrm{c}$

$\mathrm{T}_{\mathrm{r}} \quad$ room temperature, $\mathrm{c}$

$\mathrm{R}_{\mathrm{us}} \quad$ radius of upper shoulder, $\mathrm{mm}$

$\mathrm{R}_{\mathrm{ls}} \quad$ radius of lower shoulder, $\mathrm{mm}$

angular velocity

$\mathrm{T}_{\mathrm{s}} \quad$ travel speed, $\mathrm{mm} / \mathrm{min}$

\section{References}

[1] P. L. Threadgill, M. M. Z. Ahmed, J. P. Martin, J. G. Perrett, and B. P. Wynne, "The Use of Bobbin Tools for Friction Stir Welding of Aluminium Alloys," Mater. Sci. Forum, vol. 638-642, no. January, pp. 1179-1184, 2010.

[2] Meilinger and I. Torok, "The importance of friction stir welding tool," Prod. Process. Syst., vol. 6, no. 1, p. 10, 2013.

[3] E. N. C. Dalder, "A Review of Bobbin Tool Friction Stir Welding (FSW) Process," Int. J. Sci. Technol. Eng., vol. 2, 2016.

[4] Bastier, M. H. Maitournam, K. Dang Van, and F. Roger, "Steady state thermomechanical modelling of friction stir welding," Sci. Technol. Weld. Join., vol. 11, no. 3, pp. 278-288, May 2006.

[5] P. Heurtier, M. J. Jones, C. Desrayaud, J. H. Driver, F. Montheillet, and D. Allehaux, "Mechanical and thermal modelling of Friction Stir Welding," J. Mater. Process. Technol., vol. 171, no. 3, pp. 348-357, 2006.

[6] K. J. Colligan and R. S. Mishra, "A conceptual model for the process variables related to heat generation in friction stir welding of aluminum," Scr. Mater., vol. 58, no. 5, pp. 327-331, 2008.

[7] R. S. Essa, M. M. Z. Ahmed, A. K. Y. A. Mohamed, and A. E. El-Nikhaily, "An analytical model of heat generation for eccentric cylindrical pin in friction stir welding," J. Mater. Res. Technol., vol. 5, no. 3, pp. 234-240, 2016

[8] K. J. Quintana and J. L. L. Silveira, "Mechanistic models and experimental analysis for the torque in FSW considering the tool geometry and the process velocities," J. Manuf. Process., vol. 30, pp. 406-417, 2017.

[9] B. J. Stringham, T. W. Nelson, and C. D. Sorensen, "Non-dimensional modeling of the effects of weld parameters on peak temperature and cooling rate in friction stir welding," J. Mater. Process. Technol., vol. 255, no. May 2017, pp. 816-830, 2018.

[10] M. B. Durdanović, M. M. Mijajlović, D. S. Milčić, and D. S. Stamenković, "Heat generation during friction stir welding process," Tribol. Ind., vol. 31, no. 1-2, pp. 814, 2009.

[11] L. Buglioni, L. N. Tufaro, and H. G. Svoboda, "Thermal cycles and residual stresses in FSW of aluminum alloys : experimental measurements and numerical models," Procedia Mater. Sci., vol. 9, pp. 87-96, 2015

[12] V. S. Gadakh and K. Adepu, "Heat generation model for taper cylindrical pin profile in FSW," J. Mater. Res. Technol., vol. 2, no. 4, pp. 370-375, 2013.

[13] R. S. Mishra, "FRICTION STIR WELDING AND PROCESSING". Springer International Publishing Switzerland, 2014

[14] R. Nandan, G. G. Roy, T. J. Lienert, and T. Debroy, "Three-dimensional heat and material flow during friction stir welding of mild steel," Acta Mater., vol. 55, no. 3, pp. 883-895, 2007.

[15] J. T. Khairuddin, "Development of Multi Component Loads, Torque and Temperature Measurement Device for Friction Stir Welding Process," no. June, 2013.

[16] H. Schmidt, J. Hattel, and J. Wert, "An analytical model for the heat generation in friction stir welding," Model. Simul. Mater. Sci. Eng., vol. 12, no. 1, pp. 143-157, 2004.

[17] C. Hamilton, S. Dymek, and A. Sommers, "A thermal model of friction stir welding in aluminum alloys," Int. J. Mach. Tools Manuf., vol. 48, no. 10, pp. 1120-1130, 2008.

[18] M. A. Waheed, L. O. Jaiyesimi, S. O. Ismail, and O. U. Dairo, "Analytical investigations of the effects of tool pin profile and process parameters on the peak temperature in friction stir welding," J. Appl. Comput. Mech., vol. 3, no. 2, pp. 114-124, 2017.

[19] N. S. M. El-Tayeb, K. O. Low, and P. V. Brevern, “On the surface and tribological characteristics of burnished cylindrical Al-6061," Tribol. Int., vol. 42, no. 2, pp. 320326, 2009.

[20] C. Hamilton, S. Dymek, and A. Pietras, "NUMERICAL SIMULATIONS FOR BOBBIN TOOL FRICTION STIR WELDING OF ALUMINUM 6082-T6," vol. 63, pp. 11151123, 2018 